This item was submitted to Loughborough's Research Repository by the author.

Items in Figshare are protected by copyright, with all rights reserved, unless otherwise indicated.

\title{
Thermally enhanced ultrasonically assisted machining of Ti alloy
}

PLEASE CITE THE PUBLISHED VERSION

http://dx.doi.org/10.1016/j.cirpj.2014.01.002

PUBLISHER

Elsevier $\odot$ CIRP

VERSION

AM (Accepted Manuscript)

LICENCE

CC BY-NC-ND 4.0

REPOSITORY RECORD

Muhammad, Riaz, Agostino Maurotto, Murat Demiral, Anish Roy, and Vadim V. Silberschmidt. 2019.

"Thermally Enhanced Ultrasonically Assisted Machining of Ti Alloy". figshare.

https://hdl.handle.net/2134/14600. 
This item was submitted to Loughborough's Institutional Repository (https://dspace.lboro.ac.uk/) by the author and is made available under the following Creative Commons Licence conditions.



For the full text of this licence, please go to: http://creativecommons.org/licenses/by-nc-nd/2.5/ 


\title{
Thermally enhanced ultrasonically assisted machining of $\mathrm{Ti}$
}

\section{alloy}

\section{Riaz Muhammad ${ }^{a}$, Agostino Maurotto ${ }^{b}$, Murat Demiral ${ }^{c}$, Anish Roy $^{d}$, Vadim V. Silberschmidt ${ }^{\mathrm{e}}$}

Loughborough University, Wolfson School of Mechanical and Manufacturing Engineering, Loughborough University, Leicestershire, LE11 3TU, UK.

\section{a*R.Muhammad@outlook.com, ${ }^{\text {b A.Maurotto@lboro.ac.uk, }}$ 'M.Demiral@lboro.ac.uk, dA.Roy3@lboro.ac.uk, V.Silberschmidt@lboro.ac.uk}

\begin{abstract}
Recently, a non-conventional machining technique known as ultrasonically assisted turning (UAT) was introduced to machine modern alloys, in which low-energy, highfrequency vibration is superimposed on the movement of a cutting tool during a conventional cutting process. This novel machining technique, results in a multi-fold decrease in the level of cutting forces with a concomitant improvement in surface finish of machined modern alloys. Also, since the late $20^{\text {th }}$ century, machining of wear resistant materials that soften when heated have been carried out with hot machining techniques.

In this paper, a new hybrid machining technique called Hot Ultrasonically Assisted Turning (HUAT) is introduced for the processing of a Ti-based alloy. In this technique, UAT is combined with a traditional hot machining technique to gain combined advantages of both schemes for machining of intractable alloys. HUAT of the Ti alloy was analysed experimentally and numerically to demonstrate the benefits in terms of reduction in the cutting forces and improvement in surface roughness over a wide range of industrially relevant speed-feed combinations for titanium alloys.
\end{abstract}

Keywords: Ultrasonic machining; Hot ultrasonically assisted turning (HUAT); Hot machining; Ti alloy; Cutting forces; Surface roughness.

\section{Introduction}


In recent decades, titanium alloys have gained widespread application in the aerospace community primarily due to a balanced set of desirable properties, such as light weight, high-strength, good fatigue strength and resistance to corrosion. As a result, Ti alloys are gaining wider application in automotive and biomedical industries. However, these alloys are notoriously difficult to machine owing to several inherent properties of the material. These include low thermal conductivity, which impedes heat transfer out of a cutting zone, generating high process-zone temperatures. Consequently, conventional machining of these alloys leads to poor surface finish and low dimensional accuracy in machined components (Dandekar et al., 2010). Additionally, these alloys are chemically reactive with almost all cutting tool materials, impairing machinability of components (Brecher et al., 2010) features low production rates in their machining.

In the past, most machining operations benefitted from the use of cutting fluids. For manufacturing companies, the costs related to cutting fluids primarily; due to handling of cutting fluids as well as their disposal represent a large amount of the total machining costs. Therefore, dry machining is of great interest due to the current demand for green manufacturing processes (Weinert et al., 2004). Dry machining based on conventional cutting processes poses new challenges as it produces high cutting forces, poor surface finish and poor dimensional accuracy (Machai and Biermann, 2011). As a result, several finishing steps need to be incorporated into a manufacturing process in order to obtain the desired quality of components, increasing the overall machining cost.

New techniques have been proposed to improve machinability of Ti alloys, for instance, cryogenic machining with the use of carbon-dioxide snow (Machai and Biermann, 2011) and liquid nitrogen (Hong et al., 2001). Application of those new techniques affected chip shapes and also improved the surface roughness of the machined components (Yuan et al., 2011).

The shear strength and strain-hardening rate of high-strength materials decrease with an increase in temperature due to thermal softening. Therefore, external heat can be supplied to the workpiece materials to make it softer and easier for a cutting tool to remove a given amount of material, this technique is called hot machining (Ezugwu and Wang, 1997). Various types of heat sources have been used for thermal 
softening of the workpiece materials, for instance, gas torch, (Lajis et al., 2009, Maity and Swain, 2008, Ozler et al., 2001, Pal and Basu, 1971), furnace pre-heating (Amin and Talantov, 1986), induction heating (Amin et al., 2008), electric-current heating (Moriwaki et al., 1992) (Uehara et al., 1983), plasma heating (Kitagawa and Maekawa, 1990) (Germain et al., 2011, Hinds and De Almeida, 1981, Sun et al., 2008) and laser heating (Chryssolouries et al., 1997).

The flame torch is a relatively simple way to heat up a workpiece to a required temperature level. However, this method of heating cannot be used in machining of Ti-based alloys since the torch deposits carbon particles and produces a carbide layer on the specimen. Induction heating is an effective heat source in hot machining. However, it is not efficient in non-ferrous materials. The direct current could be a good alternative for heating; however, the main limitation of direct current is it dependency on cutting speed.

Laser and plasma arcs are the most effective sources of localized heating used in hot machining. However, the capital cost, requirement of high human skills and health concerns are the main obstacle for a use of these methods in hot machining.

Ultrasonically assisted turning (UAT) is a non-conventional machining technique that employs superposition of high-frequency $(f \sim 20 \mathrm{kHz}$ ) and low-amplitude ( $a \sim 15 \mu \mathrm{m}$ ) vibro-impacts on the cutting tool, preferably, in the cutting direction (Babitsky et al., 2004, Shamoto et al., 1999). The first vibration-assisted machining technique was used in the 1960s by Skelton (Skelton, 1968). This novel technique offered a significant improvement in processing of modern alloys by reducing the level of cutting forces considerably, and provide a better surface finish of machined components (Moriwaki et al., 1992). Furthermore, 2D ultrasonically assisted machining was also carried out to investigate cutting forces and surface roughness in a machined component (Shamoto et al., 1999). Recently, analytical models were developed for ultrasonically assisted oblique turning (Nategh et al., 2012) that elucidated underlying complexity of the process.

Over the last few decades, a significant amount of work has been carried out in improving the experimental setup of UAT as well as in development of numerical models of the process (Maurotto et al., 2012, Muhammad et al., 2012a, Muhammad 
et al., 2012c). A significant reduction in cutting forces was reported in machining of Ti-15V3Cr3Al3Sn designated as Ti-15333.

However, there is still a need for improvement of the machining process to further reduce cutting forces in turning of Ti-15333. So, conventional hot machining technique was combined with UAT to form a new hybrid turning process called Hot Ultrasonically Assisted Turning (HUAT). In this paper, cutting forces, temperature of the process zone and surface roughness of a workpiece machined with HUAT are analysed at various cutting conditions. To study the underlying deformation mechanism in the material, a finite element orthogonal turning model was developed to investigate stresses and temperature of the process zone in the vicinity of the cutting tool-workpiece interaction zone that is not possible in experimentations due to the opaque nature of the workpiece material.

\section{Experimental Work}

\subsection{Experimental Setup}

A universal lathe machine was appropriately modified in house to mount a band resistance heater around the cylindrical workpiece during the machining process in addition to a customised ultrasonic cutting head (Figure 1). A Kistler piezo-electric dynamometer with a sensitivity of $\pm 0.1 \mathrm{~N}$ (KIAG-SWISS Type-9257A) bolted on the cross slide of the Harrison lathe was used to record cutting forces in real time. The dynamometer has a recording frequency of $3 \mathrm{kHz}$ and is capable of force measurements up to $5 \mathrm{kN}$. The frequency of the data-acquisition system is lower than the excitation frequency of an ultrasonic transducer; as a result, average cutting forces were recorded, especially in the ultrasonic machining process. To monitor vibrational characteristics of the tool during all experimental runs, a non-contact measuring technique based on a laser vibrometer was used. 

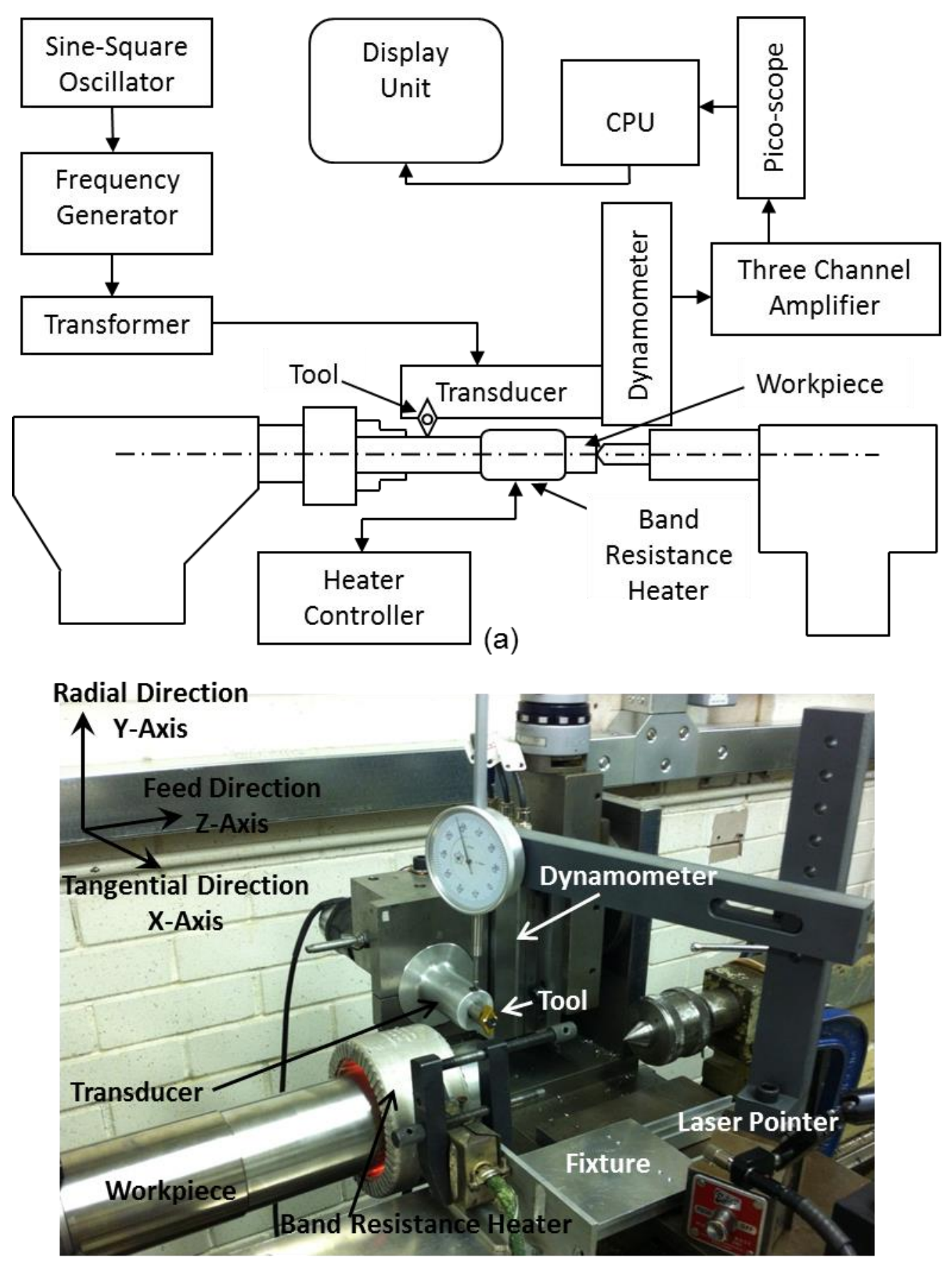

(b)

Figure 1: Schematic diagram of the experimental setup in hot ultrasonically assisted turning (a); Experimental setup used in turning tests (b)

For hot machining tests, a band-resistance heater, encapsulating the workpiece, was used as a heat source to increase the temperature of the workpiece to $300^{\circ} \mathrm{C} \pm 10^{\circ} \mathrm{C}$. For thermal measurements, a teflon coated, K-type thermocouple, with a maximum measurement range of $1200^{\circ} \mathrm{C}$ and a thermal camera (FLIR ThermaCAM ${ }^{\mathrm{TM}}$ SC3000) for real time acquisition were used. A 4-channel K-type thermometer HHM290/N 
was used to record the measured temperatures. The new Stirling-cooled Quantum Well Infrared Photon (QWIP), enable the FLIR ThermaCAM system to capture images at low-noise detection and high image stability and uniformity. Further details of the system are listed in Table 1. In experimentation, a continuous mode of recording was employed to capture a thermal distribution in the process zone in conventional and assisted turning processes. The ThermaCAM ${ }^{\circledR}$ QuickView $^{\mathrm{TM}}$ software was used to analyse the data of the FLIR ThermaCAM ${ }^{T M}$ SC3000 system. A typical temperature distribution on the surface of workpiece in hot machining at $300^{\circ} \mathrm{C}$ is shown in Figure 2.

Table 1: Features of FLIR ThermaCAM system

\begin{tabular}{lr}
\hline Image size $($ Pixel) & $320 \times 240$ \\
Temperature range $\left({ }^{\circ} \mathrm{C}\right)$ & -20 to 2000 \\
Emissivity & 0.32 \\
Spectral range $(\mu \mathrm{m})$ & $8-9$ \\
Image frequency $(\mathrm{Hz})$ & $50 / 60$ \\
Accuracy $(\%)$ & \pm 2 above $150^{\circ} \mathrm{C}$ \\
\hline
\end{tabular}

In the thermal analysis of the process zone, the heater movement was controlled manually. The camera mounted on the cross slide was moved away from the heater to avoid any thermal damage to the infrared system during the heating time, as suggested by the manufacturer. The heater was used to heat up the workpiece to a required temperature and then removed from the workpiece material during the turning test. 


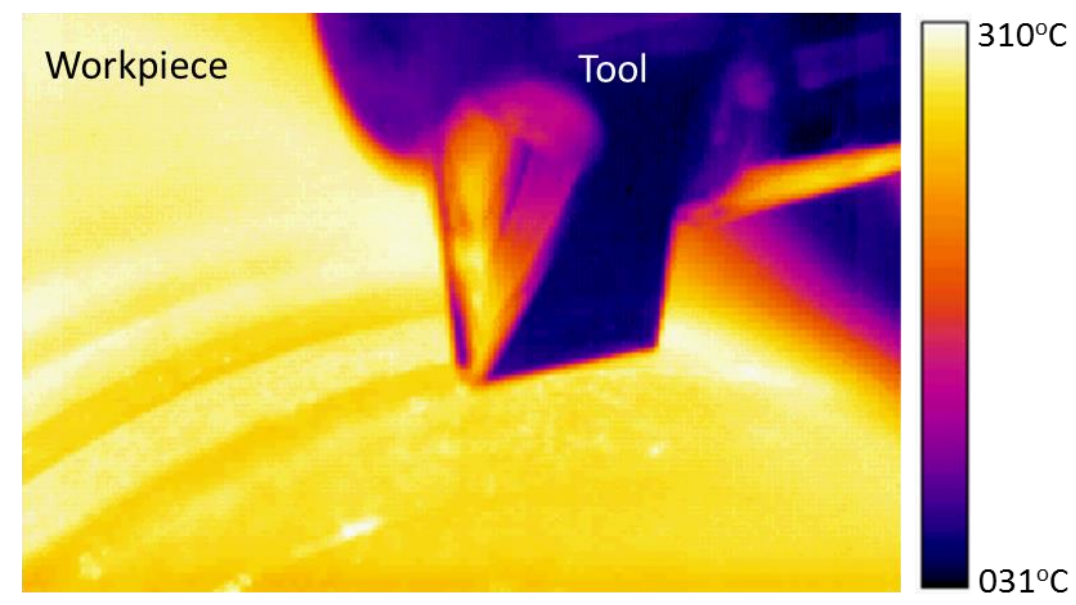

Figure 2: Infra-red image of workpiece in hot machining at $300^{\circ} \mathrm{C}$

Subsurface deformation and micro structural changes in the machined surface depend on the maximum temperature rise in the process zone in turning operation. Thus development of new tool materials as well as the advancement of machining technology will depend, to a large extent, on the knowledge and limitations of cutting temperatures that influenced the life and performance of the tool. To date, many experimental (Lajis et al., 2009), analytical (Krabacher et al., 1951), and numerical methods (Childs, 2011, Issa et al., 2012, Muhammad et al., 2012a, Muhammad et al., 2012c) were developed to determine the temperature levels during the cutting process.

\subsection{Surface Roughness and Sub-Surface Analysis}

The surface quality in machining operations directly affects machining economics (Childs, 2010). The surface topography of machined workpiece depends on machining parameters, Parameters of interface at the cutting tool tip and instability of the cutting process (chatter).

The irregularities on the surface, in different patterns, tend to form a texture that ultimately determines machining quality and is directly related to the structural integrity of machined parts. In this study, Zygo interferometry was used to analyse conventional turning (CT), hot conventional turning (HCT) and HUAT. This technique characterizes and quantifies surface roughness, step heights, critical dimensions, and other topographical features with excellent precision and accuracy. All measurements are non-destructive, fast and require no sample preparation. 
Additionally, it provides high-resolution graphical images and numerical tools to characterize accurately the surface structure of the test parts. The Zygo ${ }^{\circledR}$ interferometry instrument NewViewTM 5000 series was used for surface topology analysis of the machined workpiece.

It is well known that $\mathrm{Ti}$ alloys are sensitive to oxidation at elevated temperatures due to their high reactivity with oxygen. In the current study, the entire tests were carried in the open air without protective atmosphere. In order to investigate microstructure of a material machined with $\mathrm{CT}, \mathrm{HCT}$ and HUAT, light microscopy was carried out using Nikon Optiphot, with a GXCAM-5 acquiring system.

\subsection{Materials of Workpiece and Cutting Tool}

An ingot bar of solution-treated and aged Ti-15333 alloy with initial diameter of 68 $\mathrm{mm}$ and length $500 \mathrm{~mm}$ was used in machining experiments. The material was annealed at $790^{\circ} \mathrm{C}$ for 30 minutes followed by air cooling, resulting in the solutiontreated state consisting of $\beta$-phase. Table 2 lists some of the relevant details of workpiece material.

For all turning experiments, cemented-carbide cutting inserts were employed. The tool has a ceramic coating layer of titanium-aluminium-nitride over a layer of titanium-nitride. In conventional turning, the recommended cutting depths ranges from $200 \mu \mathrm{m}$ to $300 \mu \mathrm{m}$ with a feed rate of $50 \mu \mathrm{m} / \mathrm{rev}$ to $250 \mu \mathrm{m} / \mathrm{rev}$ and a cutting speed of $45 \mathrm{~m} / \mathrm{min}$, as specified by the manufacturer, in machining high-strength alloys. The tool has a nose radius of $800 \mu \mathrm{m}$ and a rake angle of approximately $14^{\circ}$, with a low-depth-of-cut/finishing chip breaker optimized for low feed rates. Additional details of the cutting insert are listed in Table 3.

Table 2: Material properties of Ti-15333

Workpiece material Ti-15V-3Al-3Cr-3Sn

Workpiece diameter, $D(\mathrm{~mm})$ 68

Workpiece length, $L(\mathrm{~mm})$ 500

Producer GfE Metalle and Materialien $\mathrm{GmbH}$

Heat treatment Solution-treated and aged

Young's modulus, E (GPa), at room temperature

Yield Strength, $\sigma_{y}[\mathrm{MPa}]$ 
Density, $\rho\left(\mathrm{kg} / \mathrm{m}^{3}\right)$

Thermal conductivity, $k(\mathrm{~W} / \mathrm{K} \mathrm{m})$

Co-efficient of thermal expansion, $\alpha\left[\mathrm{K}^{-1}\right]$

Specific heat, $C_{p}[\mathrm{~J} / \mathrm{g}-\mathrm{K}]$

Ultimate tensile strength, $\sigma_{u l}(\mathrm{MPa})$

1200

Table 3: Cutting tool properties

DNMG-150608-MF1-CP500

Tool maker

SECO

Tool material

Micro-grain cemented carbide

Coating

(Ti,Al)N-TiN

Tool nose radius, $r_{n}(\mu \mathrm{m})$

800

Nose angle (degree)

55

Rake angle (degree)

14.6

\subsection{Experimental Methodology}

The ingot bar of Ti-15333 was mounted on the modified lathe and the eccentricity was adjusted with the help of mechanical dial gauge. A relatively low feed rate $(t)$ of $0.1 \mathrm{~mm} / \mathrm{rev}$ was used in all the experiments. All conventional machining experiments were carried out at room temperature. Hot machining was carried out at elevated temperature of $300^{\circ} \mathrm{C}$, i.e. the workpiece was pre-heated before the start of the machining process (Table 4).

Each experimental test lasted for approximately 75 seconds. Within the first 20 seconds the depth of cut was set to the desired magnitude followed by $(\mathrm{H}) \mathrm{CT}$ for 20 seconds. Next, ultrasonic vibration was switched on for approximately 40 seconds before being switched off to recover $(\mathrm{H}) \mathrm{CT}$ cutting condition (Figure 3). Each experiment was repeated at least five times to get reasonable statistics for the experimental data. The thermal data was analysed using QuickView ${ }^{\mathrm{TM}}$ Software to take thermal history at various cutting conditions (Figure 4). 
Table 4: Cutting conditions used in experiments

\begin{tabular}{lr}
\hline Parameters & Magnitude \\
\hline Cutting speed, $V(10 \mathrm{~m} / \mathrm{min})$ & 10 \\
Depth of cut, $a_{p}(\mu \mathrm{m})$ & $100-500$ \\
Feed rate, $t(\mathrm{~mm} / \mathrm{rev})$ & 0.1 \\
In HCT and HUAT: Temperature, $T\left({ }^{\circ} \mathrm{C}\right)$ & 300 \\
In (H)UAT: Frequency, $f(\mathrm{kHz})$ & 20 \\
In $(\mathrm{H})$ UAT: Amplitude, $a(\mu \mathrm{m})$ & 8 \\
\hline
\end{tabular}

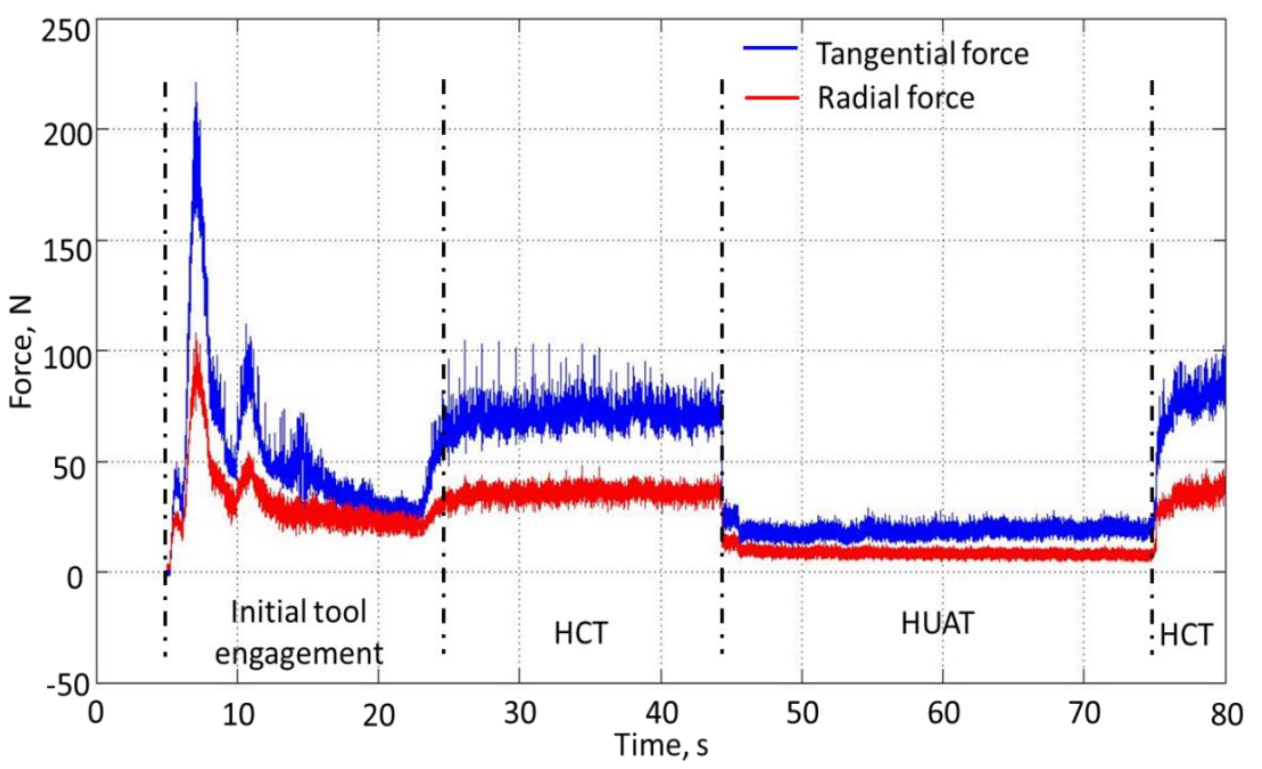

Figure 3: Force history in experimentation at $300^{\circ} \mathrm{C}\left(V=10 \mathrm{~m} / \mathrm{min} ; a_{p}=300 \mu \mathrm{m}\right)$ 


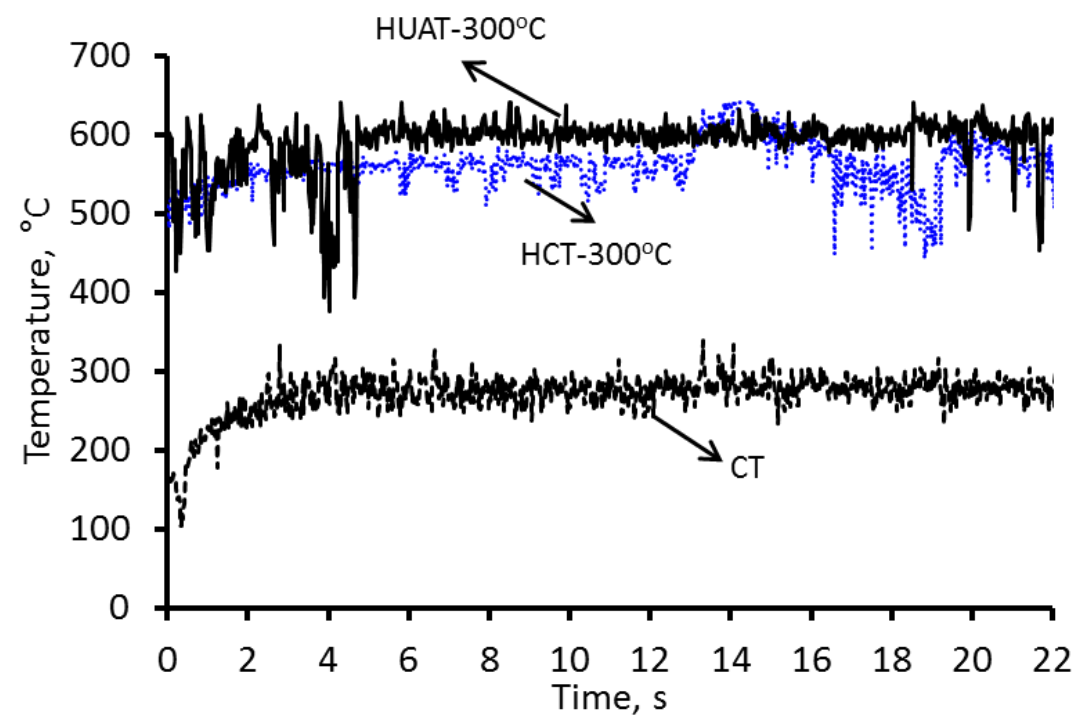

Figure 4: Temperature history of process zone for various machining techniques $(V=$

$$
10 \mathrm{~m} / \mathrm{min} ; a_{p}=300 \mu \mathrm{m} \text { ) }
$$

For surface roughness analysis, the experiments time was increased to get an appropriate surface area for measurement of surface topology. A bar of Ti-15333 was turned for a distance of $10 \mathrm{~mm}$ in the axial direction (Z-axis in Figure $1 \mathrm{~b}$ ) using CT. Similarly, the same procedure was repeated for HCT and HUAT keeping the same cutting conditions apart vibration and temperature to analyse surface roughness of a machined specimen. Light microscopy of a machined specimen was carried out to investigate the effect of externally applied heat and temperature generated in the process zone in conventional and assisted turning processes.

\section{Experimental Results and Discussion}

\subsection{Cutting Forces}

Cutting forces were measured in a real time regime during the machining operation for various depths of cut $\left(a_{p}\right)$. A substantial reduction in tangential and radial components of forces was observed in turning of Ti-15333 using HUAT when compared to conventional machining conditions (Figure 5). At $a_{p}=100 \mu \mathrm{m}$ the reduction in those components of cutting forces was approximately $95 \%$ in HUAT when compared to $\mathrm{CT}$. The decline in cutting forces reduced with an increase in the depth of cut and, ultimately, a uniform reduction of $80-85 \%$ was observed in HUAT above $200 \mu \mathrm{m}$ (Figure 6). On the other hand, a reduction of approx. 20\% in cutting forces was achieved in HCT. 

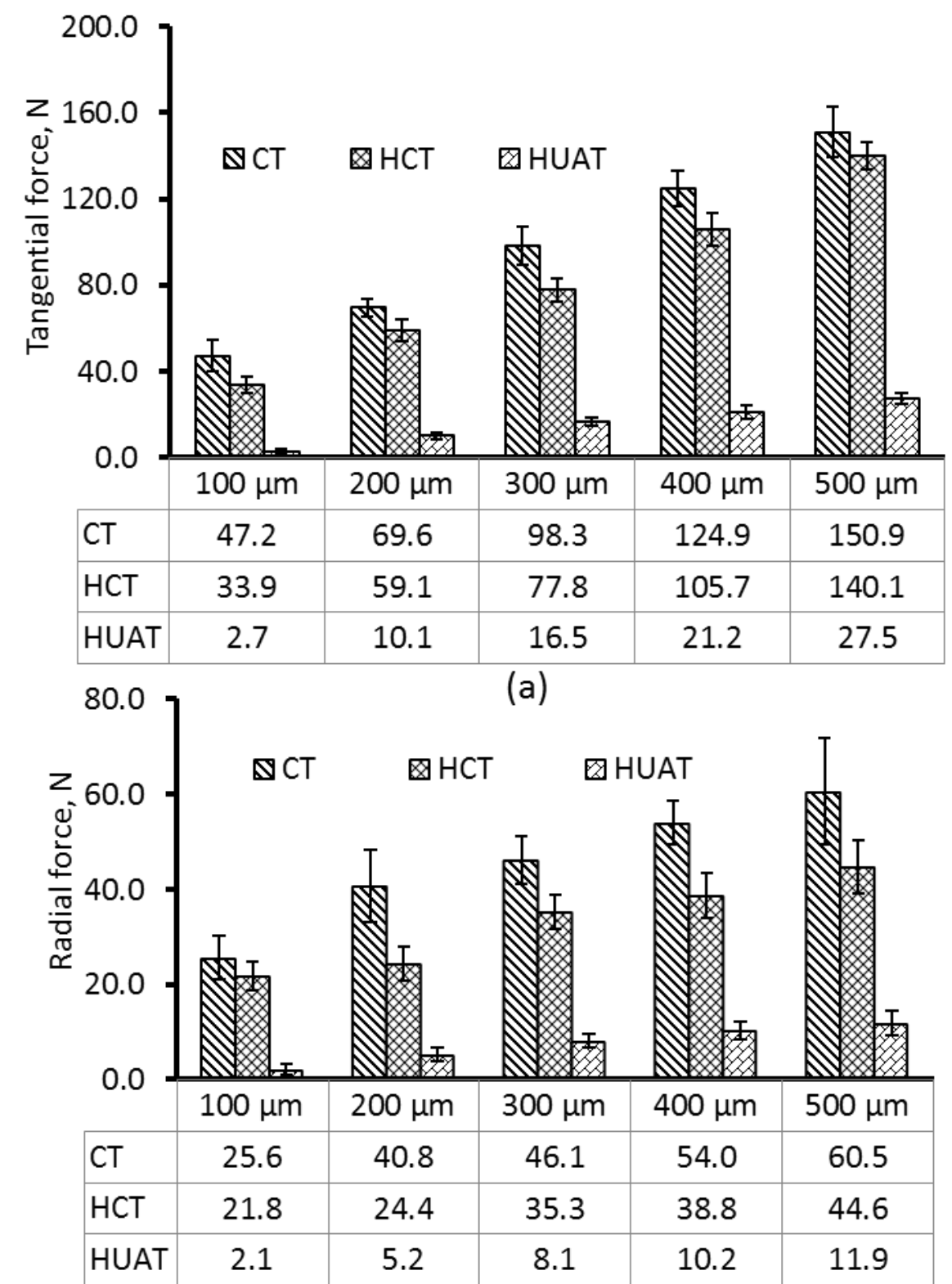

(b)

Figure 5: Cutting forces at various depth of cut (a) Tangential force; (b) Radial force $\left(V=10 \mathrm{~m} / \mathrm{min} ; T=300^{\circ} \mathrm{C}\right)$

In hot machining, the reduction in cutting forces is mainly attributed to the decreasing yield strength of Ti-15333 at elevated temperatures (Muhammad et al., 2012b). However, in HUAT, thermal softening when combined with tool separation in each vibratory cycle of tool movement resulted in a significantly higher force reduction compared to other machining processes. 


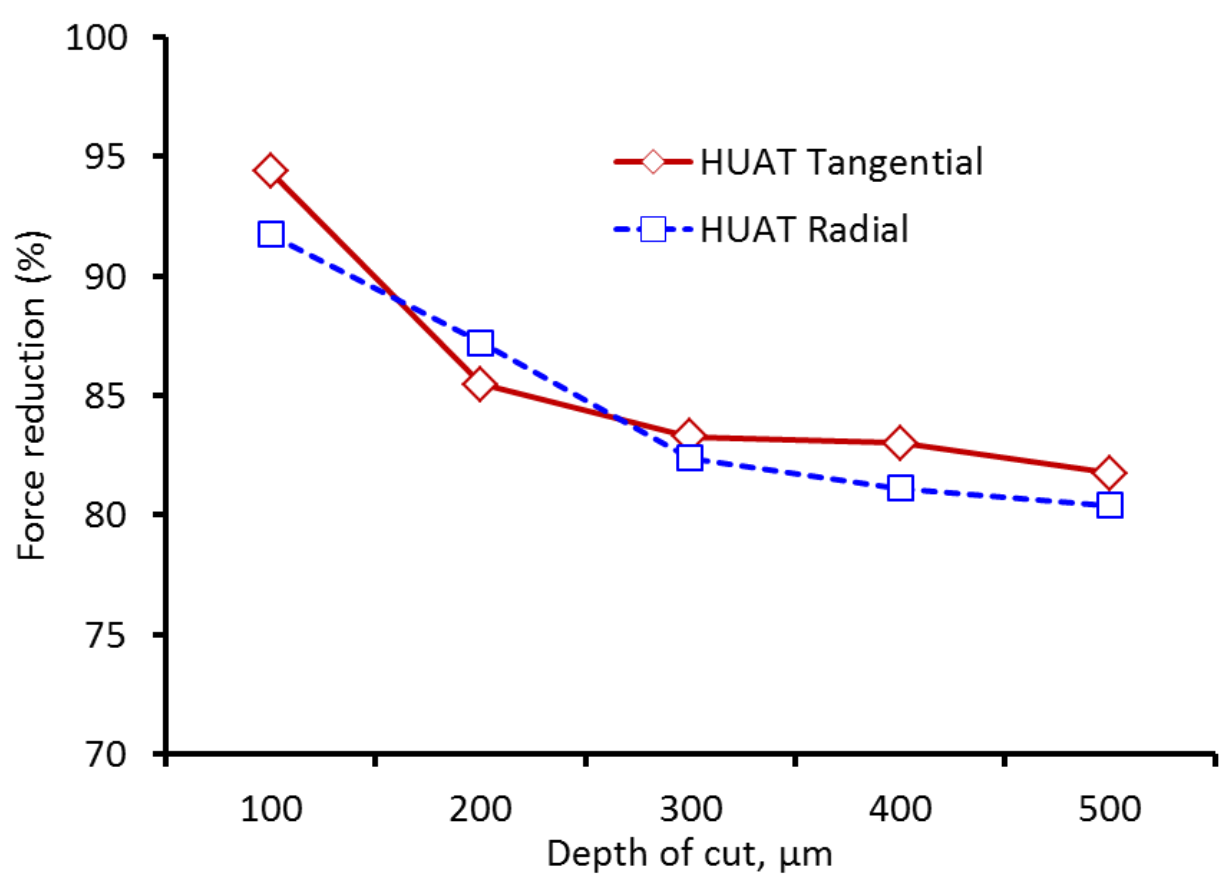

Figure 6: Reduction in cutting forces in HUAT when compared to CT at various depth of cut, $\left(V=10 \mathrm{~m} / \mathrm{min} ; T=300^{\circ} \mathrm{C}\right)$

\subsection{Thermal Analysis}

A special study was undertaken to track the process-zone temperatures in $\mathrm{CT}$, HCT and HUAT. In this section, thermal results obtained at various cutting conditions in CT, HCT and HUAT are analysed in detail. It was observed that the temperature of the process zone increases with the application of external heat to the workpiece material. The temperature of the cutting region in HCT (where the workpiece was heated to $300^{\circ} \mathrm{C}$ before machining) at $a_{p}=300 \mu \mathrm{m}$, was approximately $250^{\circ} \mathrm{C}$ higher when compared to that in conventional turning whereas in HUAT the temperature was some $300^{\circ} \mathrm{C}$ higher (Figure 7). The temperature increase at the process zone was gradual with time after the initial engagement of the tool; the temperature was observed to reach a steady state within the first 10 seconds of machining. In HCT, some fluctuations were noticeable for approx. 15 seconds (Figure 4) due to the chip obstructing the direct line of sight to the workpiece. The steady-state temperature in $\mathrm{HCT}$ was verified in additional experimental runs. In HUAT, a higher temperature at the process zone was observed when compared to HCT. This is attributed to the temperature rise due to energy dissipation from vibro-impacts imposed on the workpiece via the cutting tool in ultrasonic machining. 


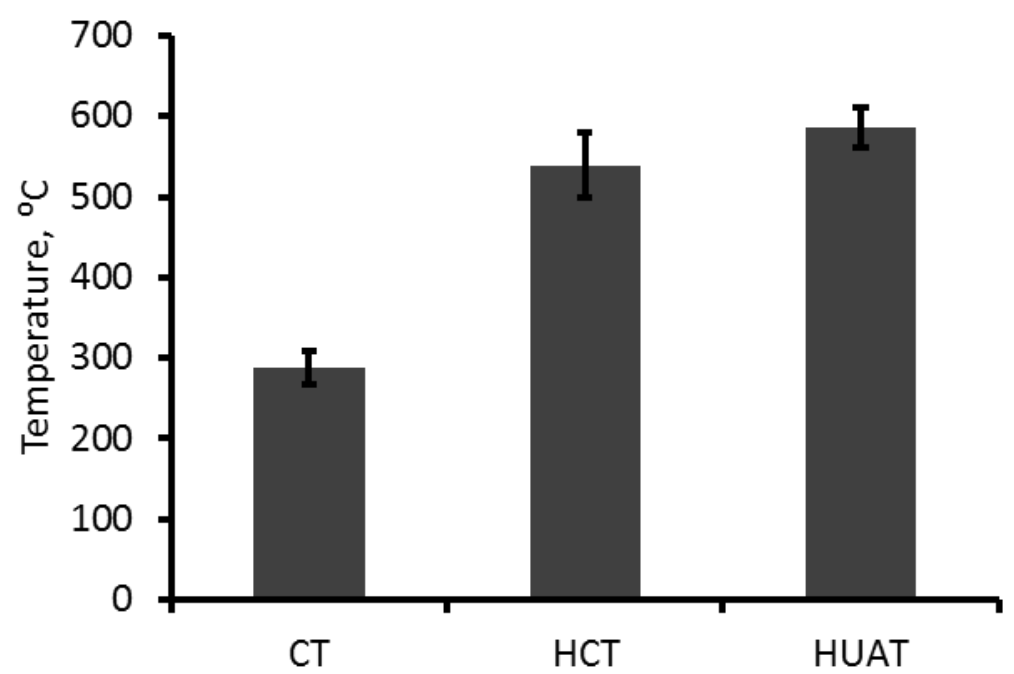

Figure 7: Temperature in process zone for various machining techniques $(V=10$ $\mathrm{m} / \mathrm{min} ; a_{p}=300 \mu \mathrm{m}$ )

\subsection{Surface Roughness Analysis}

Characterisation of surface topography of the finished workpiece is essential in assessing machining quality. Insights into the fatigue strength of the machined component may also be gained from such a study (Korzynski et al., 2011).

In the present study, surface roughness of the machined workpiece was analysed for $\mathrm{CT}, \mathrm{HCT}$ and HUAT at $a_{p}=300 \mu \mathrm{m}$. The universally used centre-line average amplitude parameter $\left(R_{a}\right)$ and the areal field parameters-root mean square of the height $\left(S_{q}\right)$ and arithmetic mean of the absolute height $\left(S_{a}\right)$ (Leach, 2010)-were used to describe the surface topography.

A significant reduction in all roughness parameters was observed for HUAT and HCT when compared to CT (Figure 8). In HUAT, an improvement in surface topography parameters in excess of $50 \%$ was found. Therefore, a significantly improved surface quality in the newly developed hybrid machining process was demonstrated. Figure 9 compares the underlying texture of typical surfaces machined. These are represented as 2D field plots. Distinct periodicity can be observed for the conventionally turned surface whereas for the enhanced machining technique this regularity is somewhat curtailed. The surface quality in HCT and HUAT was the same in statistical terms. 


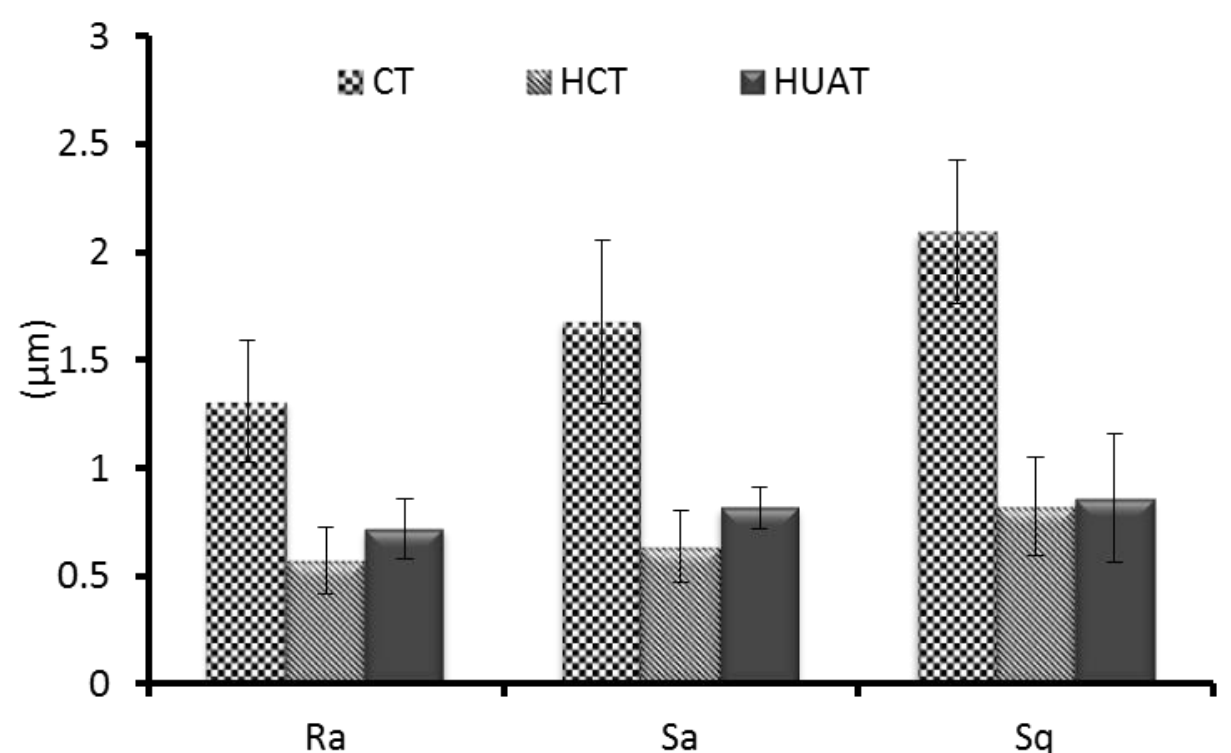

Figure 8: Surface roughness at various temperatures $\left(V=10 \mathrm{~m} / \mathrm{min} ; a_{p}=300 \mu \mathrm{m}\right)$

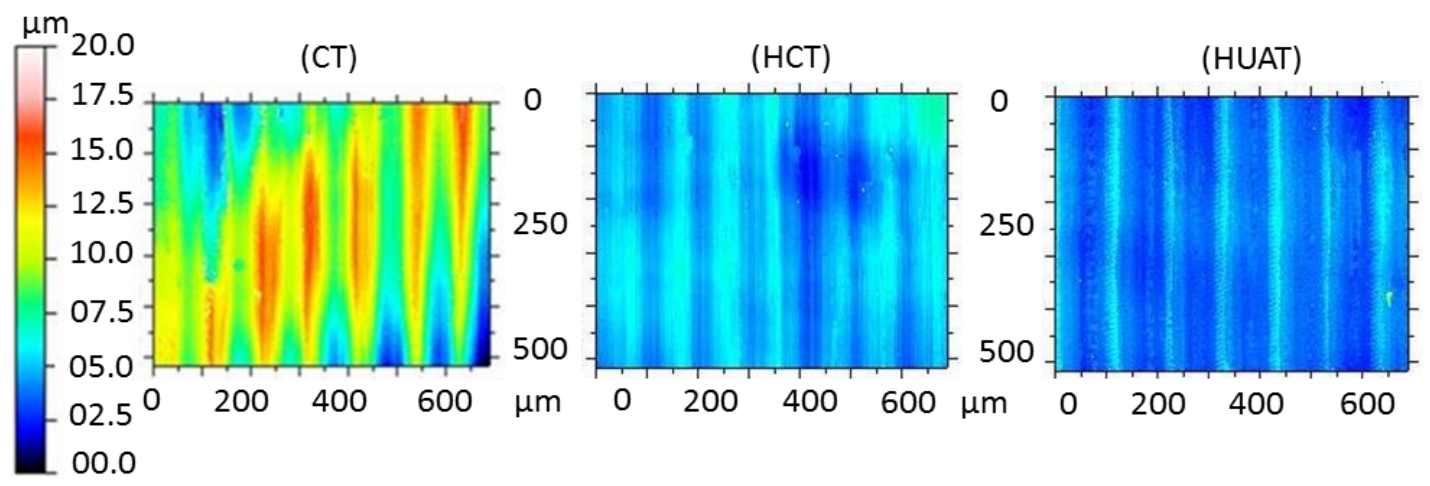

Figure 9: Contour plot of surface roughness $\left(V=10 \mathrm{~m} / \mathrm{min} ; a_{p}=300 \mu \mathrm{m}\right)$

Light-microscopy scans of the machined specimens were carried out to look for signs of oxidation and microstructural changes. It was found that the grain size in Ti-15333 was non-uniform; this is the case in the virgin state as well (Dodonov et al., 2009). It is known that is the material when subjected to temperatures above $450^{\circ} \mathrm{C}$ for more than one hour, needle-like precipitate appeared on the alloys surface (Dodonov et al., 2009). The specimens were investigated at different magnification and no signs of oxidation or metallurgical changes were observed as shown in Figure 10. It was concluded that the external heat of $300^{\circ} \mathrm{C}$ applied to the workpiece had no detrimental effect on its material characteristics. It is to be noted that the temperature in the process zone was observed to be as high as $589^{\circ} \mathrm{C}$ for $a_{p}=300$ $\mu \mathrm{m}$ in HUAT; however, with the exposure time being relatively short (in comparison to one hour), no precipitates were observed to form. 


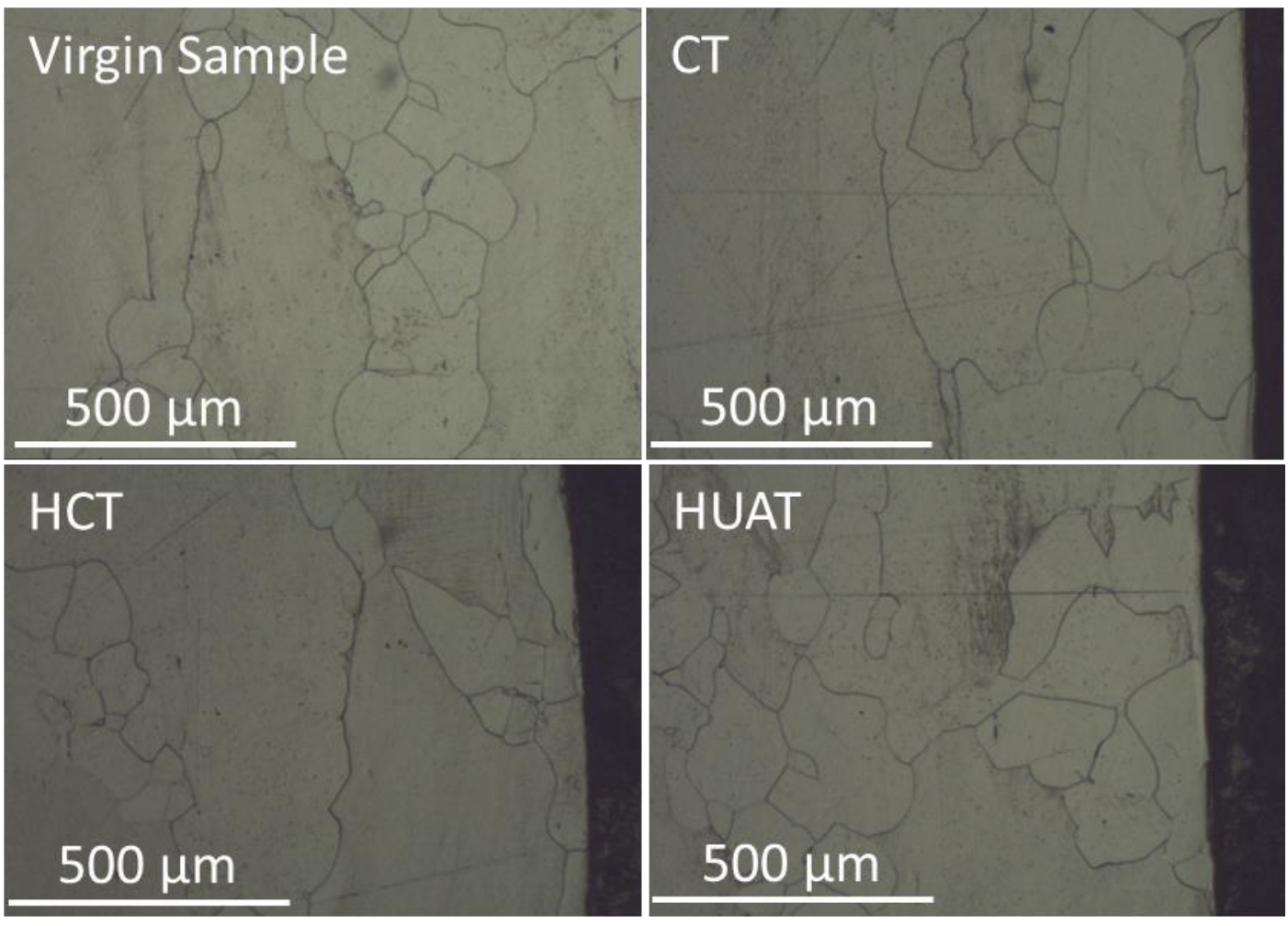

Figure 10: Light microscopy of sub-surface layers in Ti-15333 in as delivered state and after various machining technique $\left(V=10 \mathrm{~m} / \mathrm{min} ; a_{p}=500 \mu \mathrm{m}\right)$

\section{Numerical Modelling}

\section{1. $\quad$ Model}

A finite element (FE) analysis was used to carry out implicit 3D thermo-mechanically coupled orthogonal turning simulations of $\mathrm{CT}, \mathrm{HCT}$ and HUAT. A schematic of the orthogonal turning process is shown in Figure 11. A deformable workpiece with dimensions of $3.0 \mathrm{~mm}$ in length and $0.7 \mathrm{~mm}$ in height was used; these dimensions were deemed appropriate to demonstrating the underlying mechanical principles in the studied machining problem. The workpiece was translated in the tangential direction with a constant velocity, $V$. Initially, eight-node hexahedral elements with a minimum and a maximum element size of $0.025 \mathrm{~mm}$ and $0.1 \mathrm{~mm}$, respectively, were used to mesh the workpiece. The cutting tool was assumed to be rigid with heat transfer capabilities. Harmonic oscillation with given amplitude (a) and frequency $(f)$ in the tangential direction is then superimposed on the cutting tool's movement in order to model ultrasonic vibration of the tool. The tool was modelled with a cutting edge radius of $25 \mu \mathrm{m}$ and a rake angle of $14.5^{\circ}$. The tool geometry was discretized into 8000 eight-node iso-parametric, irregular quadrilateral elements. For 
improved computational accuracy and efficiency, a refined mesh at the tool tip was used with a coarse mesh elsewhere (Figure 11). Pre-heating of the material was incorporated into the model by imposing initial temperature to the workpiece.

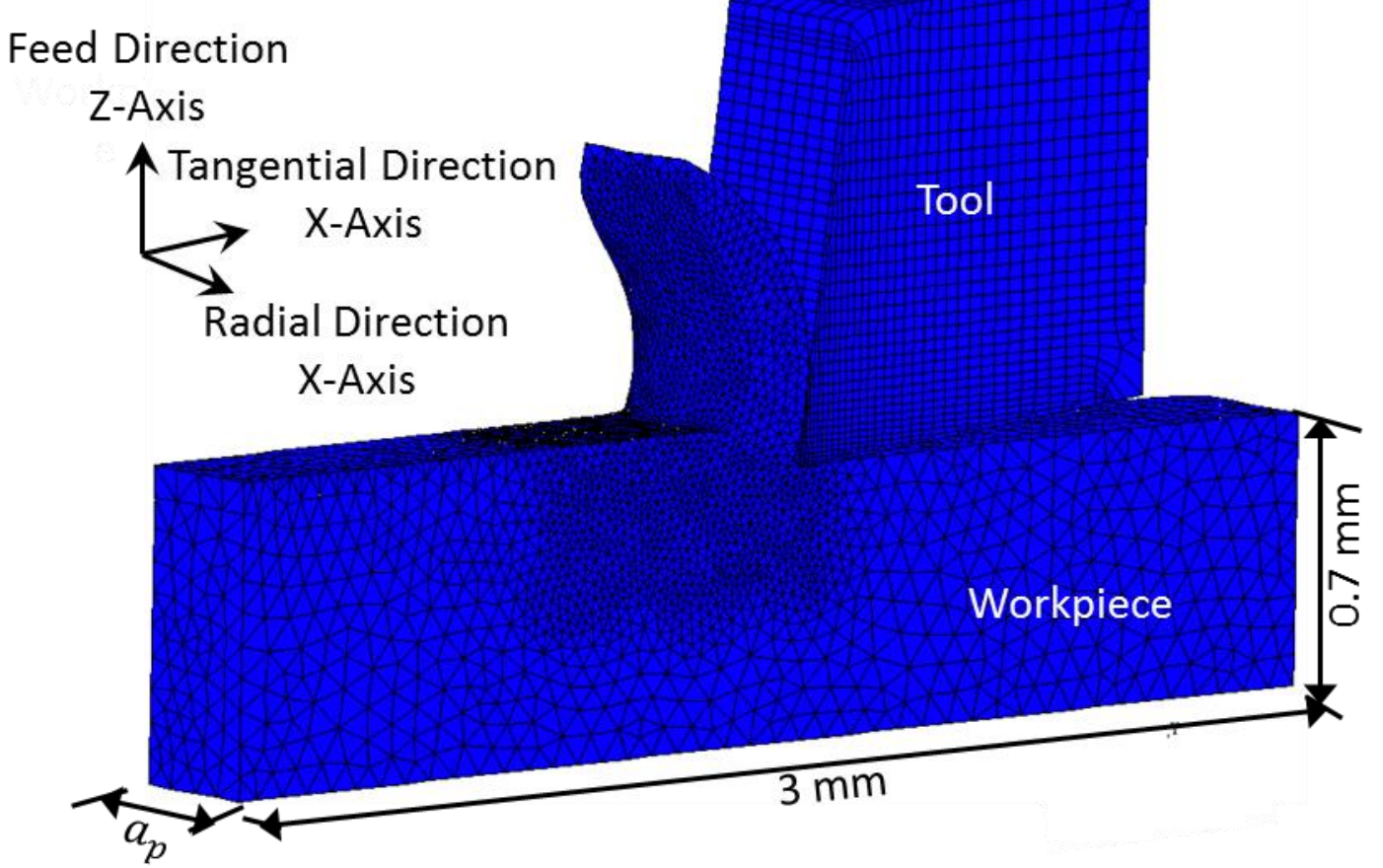

Figure 11: Schematic of cutting model

For accurate predictive capabilities, a representative material model of thermomechanical behaviour of Ti-15333 at elevated temperatures and high strain rates was implemented. To obtain flow stress behaviour at known temperature and strain rate, a series of split-Hopkinson pressure bar tests was carried out for the studied Tialloy at Tampere University of Technology, Finland, the details of the test data can be found elsewhere (Muhammad et al., 2012a).

Interface properties between the tool and workpiece are critical in determining the machining characteristics. To this end, a modified shear friction model was implemented to simulate transient slip-stick behaviour. The frictional stress, $\sigma_{\mathrm{fr}}$, is introduced in the following form:

$\sigma_{\mathrm{fr}} \leq-m_{\mathrm{fr}} \frac{\bar{\sigma}}{\sqrt{3}} \frac{2}{\pi} \operatorname{sgn}\left(\mathrm{V}_{\mathrm{r}}\right) \operatorname{artan}\left(\frac{V_{\mathrm{r}}}{V_{\mathrm{cr}}}\right)$, 
where $\bar{\sigma}$ is the equivalent stress, $V_{\mathrm{r}}$ is the relative sliding velocity, $V_{\mathrm{cr}}$ is the critical sliding velocity below which sticking is simulated, $m_{\mathrm{fr}}$ is the friction coefficient and $\operatorname{sgn}(\mathrm{x})$ is the signum function.

\section{Numerical Results and Discussions}

\subsection{Cutting Forces}

The application of an external heat source to the workpiece material reduces the cutting forces, as the shear strength of a material reduces with an increase in temperature. Therefore, at elevated temperatures the material becomes softer and it is easier for the tool to remove the given amount of material.

In $\mathrm{CT}$ and $\mathrm{HCT}$, the cutting tool was in continuous contact with the workpiece resulting a constant magnitude of the cutting force, whereas, in HUAT the tool separated from the workpiece during the relaxation stage of each cycle of vibration, resulting in a cutting force fluctuating between a peak value and zero (Figure 12). The cutting force in HCT was lower in the magnitude when compared to CT due to the thermal softening of the workpiece material as expected. This effect also translated to HUAT where a reduction in the peak force value was observed. Numerically, the effect of imposing an initial temperature of $500^{\circ} \mathrm{C}$ was in addition to the experimentally employed hot-machining temperature of $300^{\circ} \mathrm{C}$. A gradual reduction in the tangential cutting force was observed with an increase in external heat supplied to the workpiece material. 


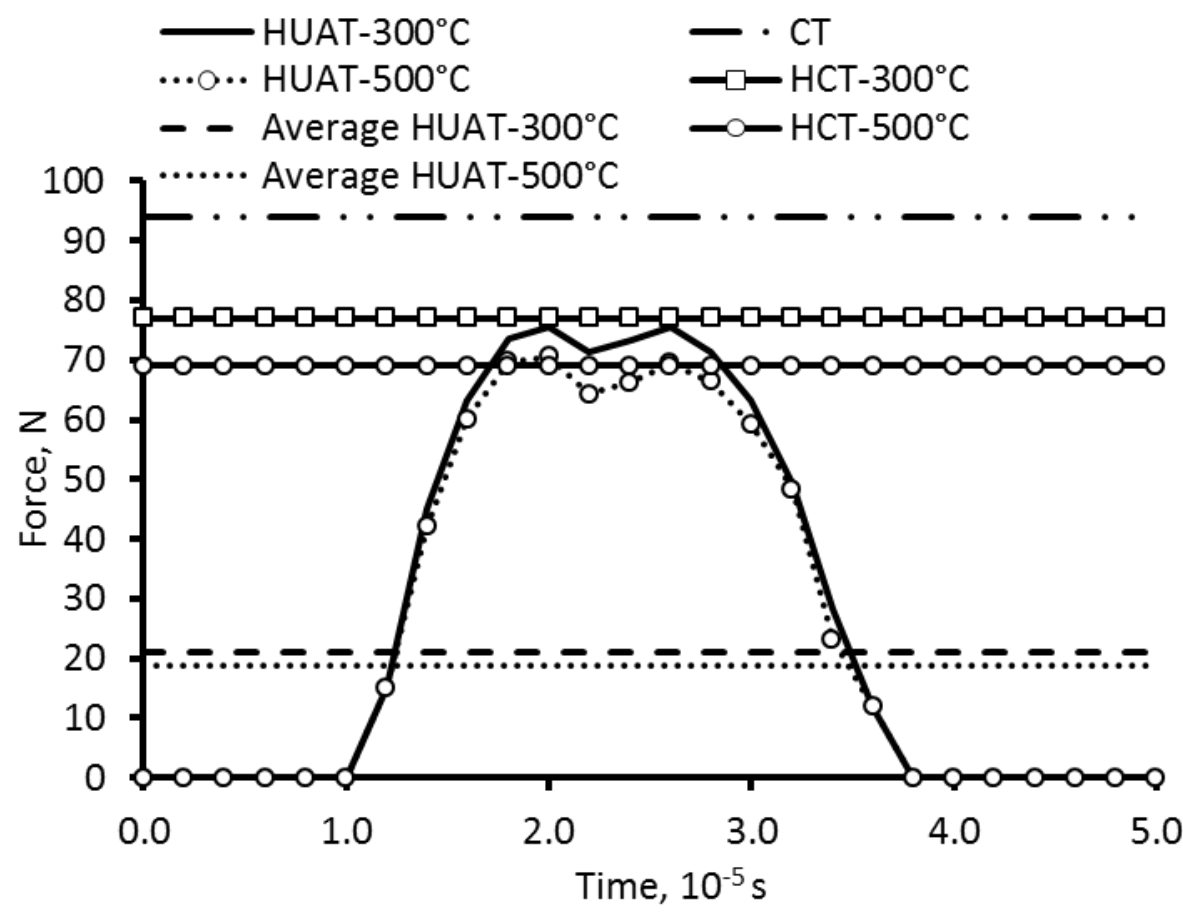

Figure 12: Tangential components of cutting force in machining Ti-15333 with various techniques and temperature $\left(V=10 \mathrm{~m} / \mathrm{min} ; a_{p}=300 \mu \mathrm{m} ; f=20 \mathrm{kHz} ; a=8\right.$ $\mu \mathrm{m})$

From the FE simulations followed that the cutting forces were reduced approx. 78\% at $300^{\circ} \mathrm{C}$ and $80 \%$ at $500^{\circ} \mathrm{C}$ when compared to the forces obtained with CT at $a_{p}=$ $300 \mu \mathrm{m}$. Overall, a good agreement between the experimental and numerical results was achieved in the current study as shown in Figure 13. Our studies indicate that an increase in temperature of hot machining does not necessarily yield tractable benefits with respect to force reductions. At $500^{\circ} \mathrm{C}$ the reduction in cutting forces is comparable to that for workpiece heating temperature of $300^{\circ} \mathrm{C}$. Thus, from the current study, a temperature of $300^{\circ} \mathrm{C}$ in hot machining of Ti-15333 can be recommended. 


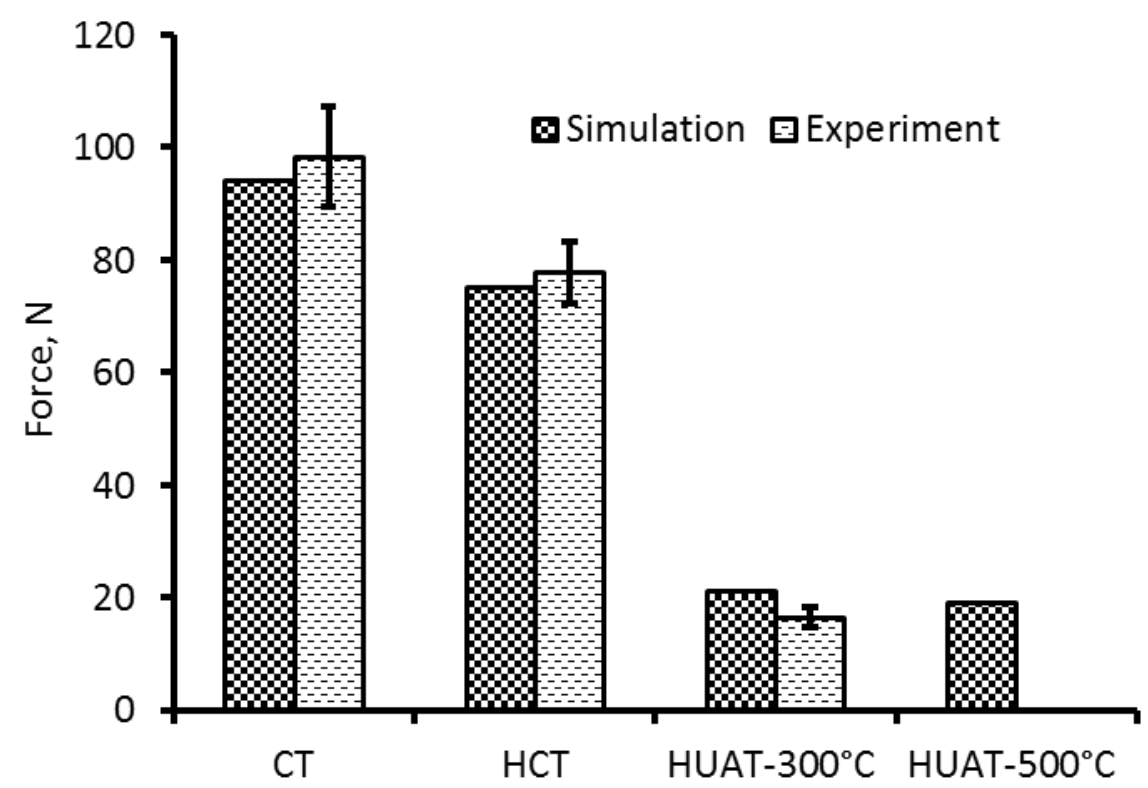

Figure 13: Tangential component of cutting forces in CT, HCT and HUAT ( $V=10$ $\mathrm{m} / \mathrm{min} ; a_{p}=300 \mu \mathrm{m}$ )

\subsection{Temperature of Process Zone}

The temperature of the cutting region was also analysed numerically for various cutting conditions in HUAT. For comparison, the results of HUAT were related to those in $\mathrm{CT}$ and $\mathrm{HCT}$. The temperature of the cutting region was observed to grow with an increase of heat externally applied to the workpiece in HUAT. The growing temperature of the process zone aids in reducing the shear strength of the material and, as result, the overall lower cutting force. The temperature distribution at the process zone in CT, HCT and HUAT is shown in Figure 14.

In turning experiments, infra-red thermography performed had some limitations, primarily due to obstruction from the chip during the machining operation. The temperature magnitudes in the visible regions of the thermal camera in experimentation are in good agreement with the obtained simulated results. The FE models have the added advantage of elucidating the temperature characteristics in regions of the workpiece not visible to thermal imaging. In HUAT, a relatively high temperature at the process zone was observed. The peak temperature was $660^{\circ} \mathrm{C}$, in comparison to approx. $600^{\circ} \mathrm{C}$ measured in experiments. The temperature in the process zone in HUAT during penetration and full retraction in each cycle of vibration varied by approximately, $50^{\circ} \mathrm{C}$. Figure 14 shows the temperature profiles in the workpiece material for various studied machining process. 


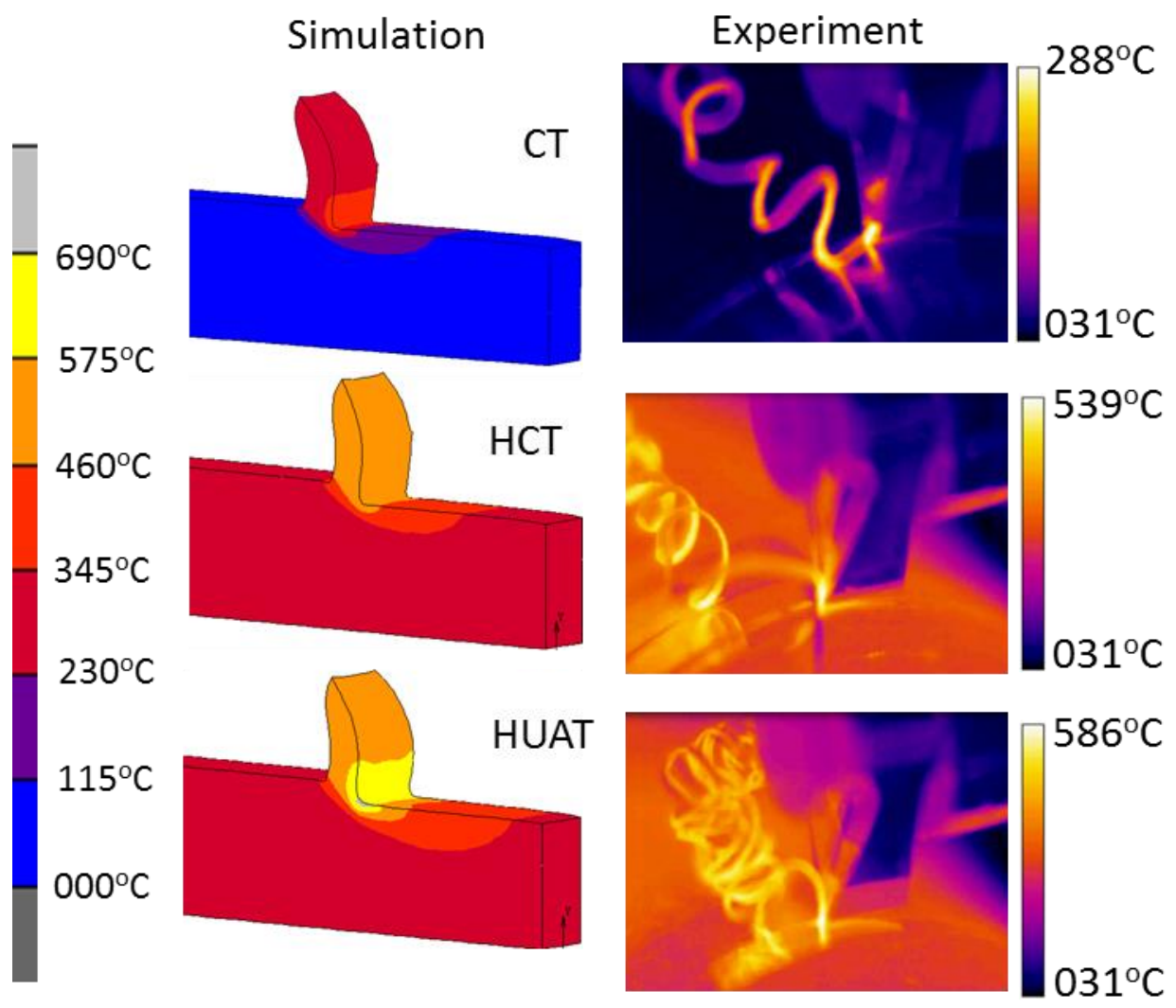

Figure 14: Temperature of the process zone in CT, HCT and HUAT ( $t=8 \mathrm{~ms})$

In addition, the amount of heat transfer to the cutting tool from the process zone was also investigated. As expected, a high-temperature distribution was observed along the tool rake face in the direction of chip flow. A maximum temperature of $318^{\circ} \mathrm{C}$ was found on the rake face in HUAT at the penetration stage. A slight reduction of $7^{\circ} \mathrm{C}$ in that area was observed in the retraction stage. On average, a temperature level of $314^{\circ} \mathrm{C}$ was observed in one complete vibratory cycle. The reduction in temperature at the retraction stage in HUAT may be attributed to convection heat transfer from the cutting tool. The temperature in HUAT is close to that of the rake face temperature in $\mathrm{HCT}\left(309^{\circ} \mathrm{C}\right)$.

\subsection{Stresses in Process Zone}

The calculated distributions of von-Mises stresses in the cutting regions of the studied alloy for CT, HCT and HUAT are shown in Figure 15 with the tool position at the maximum penetration stage (maximum stress) for the last technique. In CT and $\mathrm{HCT}$, the stress distribution was concentrated in two main regions called primary and secondary regions, while in HUAT, it was transient and changed during each vibration cycle 
In HUAT, the stress value reduces due to the thermal softening of material by the externally applied heat. The stress magnitude at the cutting region at the maximum penetration in HUAT $\left(300^{\circ} \mathrm{C}\right)$ was $800 \mathrm{MPa}$; it dropped significantly at the relaxation stage when the tool separated from the workpiece. The stress level in HCT is nearly the same as the peak stress in HUAT. As soon as the tool comes into contact with the chip again at the next penetration stage of HUAT, the value of stresses reached to the maximum values and, thus, the cycle was repeated. The average levels of the von-Mises stress in the cutting region in one complete cycle in HUAT was lower than that of $\mathrm{CT}$ and $\mathrm{HCT}$.

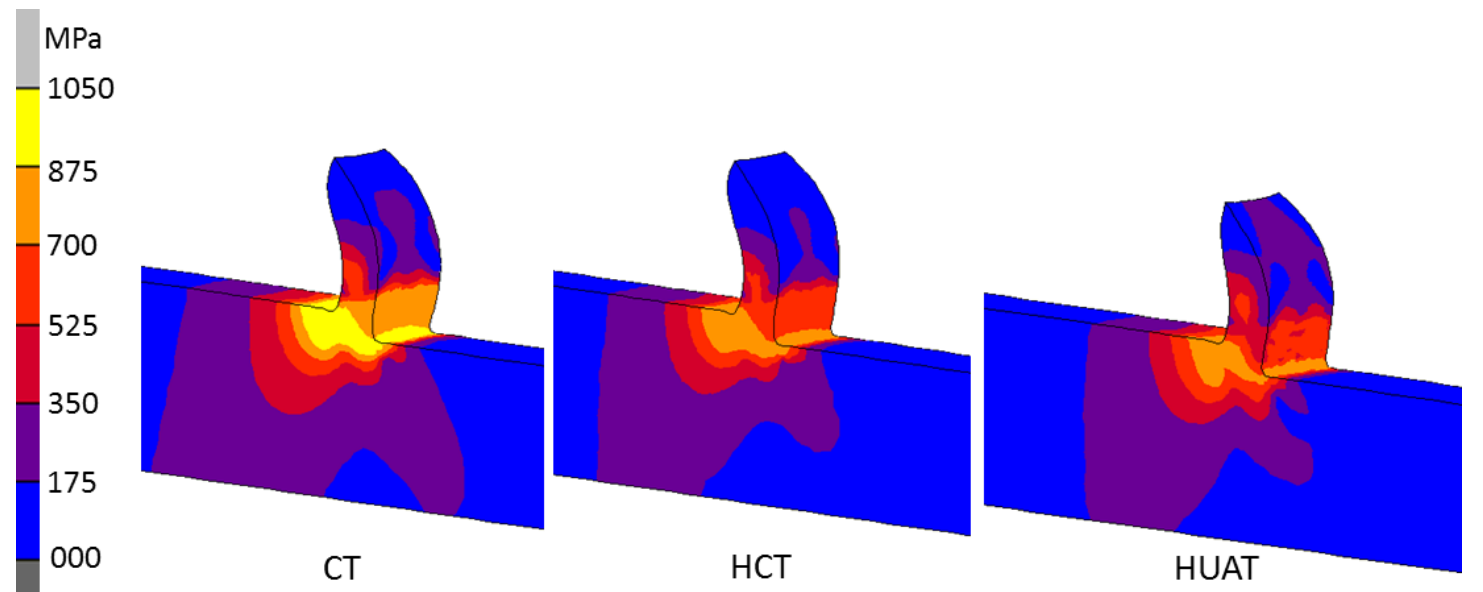

Figure 15: Stress distribution in process zone in CT, HCT and HUAT

\section{Summary and Conclusions}

In this paper, a novel hybrid machining process - hot ultrasonically assisted turning (HUAT) - is presented for the machining of a $\beta$-Ti alloy. Advantages in terms of force reduction and surface topology improvement were studied; the analysis was carried both experimentally and numerically and the following conclusions were derived:

- A significant reduction in cutting forces was observed in HUAT, often in excess of $80-85 \%$ when compared to conventional machining techniques.

- The temperature at the process zone increased with the application of external heat to the workpiece material.

- Application of an external heat source improved the surface roughness of a machined specimen both in HCT and HUAT. 
- A numerical model was developed for the novel turning process and results obtained from simulations with the model were in good agreement with the experimental data.

\section{Acknowledgements}

This work was supported by the European Union Seventh Framework Program (FP7/2007-2013) under grant agreement No. PITN-GA-2008-211536, project MaMiNa.

The authors would also like to acknowledge Engineering and Physical Sciences Research Council (EPSRC), UK for providing FLIR SC3000 system for thermal analysis.

\section{References}

Amin AKMN, Dolah SB, Mahmud MB, Lajis MA. Effects of workpiece preheating on surface roughness, chatter and tool performance during end milling of hardened steel D2. Journal of Materials Processing Technology. 2008;201:466-70.

Amin AKMN, Talantov NV. Influence of instability of chip formation and preheating of work on tool life in machining high temperature resistance steel and titanium alloy. Mechanical Engineering Research Bulletin. 1986;9:52-62.

Babitsky VI, Mitrofanov AV, Silberschmidt VV. Ultrasonically assisted turning of aviation materials: simulations and experimental study. Ultrasonics. 2004;42:81-6.

Brecher C, Rosen C-J, Emonts M. Laser-assisted milling of advanced materials. Physics Procedia. 2010;5, Part B:259-72.

Childs THC. Surface energy, cutting edge radius and material flow stress size effects in continuous chip formation of metals. CIRP Journal of Manufacturing Science and Technology. 2010;3:27-39.

Childs THC. Towards simulating built-up-edge formation in the machining of steel. CIRP Journal of Manufacturing Science and Technology. 2011;4:57-70.

Chryssolouries G, Anifantis N, Karagiannis S. Laser assisted machining: an overview. Journal of Manufacturing Science and Engineering, Transactions of the ASME. 1997;119:766-9. 
Dandekar CR, Shin YC, Barnes J. Machinability improvement of titanium alloy (Ti$6 \mathrm{Al}-4 \mathrm{~V})$ via LAM and hybrid machining. International Journal of Machine Tools and Manufacture. 2010;50:174-82.

Dodonov A, Siemers C, Rosler J. Analysis of the processing and machining characteristics of Ti15V3Al3Sn3Cr alloy. 7th International Conference on Modern Practice in Stress and Vibration Analysis. Cambridge, UK2009. p. 1-14.

Ezugwu O, Wang M. Titanium alloys and their machinability-a review. Journal of Materials Processing Technology. 1997;68:262-74.

Germain G, Dal Santo P, Lebrun JL. Comprehension of chip formation in laser assisted machining. International Journal of Machine Tools and Manufacture. 2011;51:230-8.

Hinds BK, De Almeida SM. Plasma arc heating for hot machining. International Journal of Machine Tool Design and Research. 1981;21:143-52.

Hong SY, Ding Y, Jeong W-c. Friction and cutting forces in cryogenic machining of Ti6AI-4V. International Journal of Machine Tools and Manufacture. 2001;41:2271-85.

Issa M, Labergère $C$, Saanouni $K$, Rassineux A. Numerical prediction of thermomechanical field localization in orthogonal cutting. CIRP Journal of Manufacturing Science and Technology. 2012;5:175-95.

Kitagawa T, Maekawa K. Plasma hot machining for new engineering materials. Wear. 1990;139:251-167.

Korzynski M, Zarski T, Korzynska K. Surface layer condition and the fatigue strength of an AZ91 alloy after ball peening. Journal of Materials Processing Technology. 2011;211:1982-8.

Krabacher EJ, Marchant ME, Ohio C. Basic factors in hot-machining of metals. Transaction of American Society of Mechanical Engineers. 1951;73:761-76.

Lajis MA, Amin AKMN, Karim ANM, Radzi HCDM, Ginta TL. Hot machining of hardened steels with coated carbide inserts. American Journal of Engineering and Applied Sciences. 2009;421-427.

Leach R. Fundamental principles of engineering nano-metrology. Amsterdam: Elsevier; 2010. 
Machai C, Biermann D. Machining of $\beta$-titanium-alloy Ti-10V-2Fe-3Al under cryogenic conditions: Cooling with carbon dioxide snow. Journal of Materials Processing Technology. 2011;211:1175-83.

Maity KP, Swain PK. An experimental investigation of hot-machining to predict tool life. Journal of Materials Processing Technology. 2008;198:344-9.

Maurotto A, Muhammad R, Roy A, Babitsky VI, Silberschmidt VV. Comparing machinability of Ti-15-3-3-3 and Ni-625 alloys in UAT. Procedia CIRP. 2012;1:330-5.

Moriwaki T, Shamoto E, Inoue K. Ultraprecision ductile cutting of glass by applying ultrasonic vibration. CIRP Annals - Manufacturing Technology. 1992;41:141-4.

Muhammad R, Ahmed N, Roy A, Silberschmidt VV. Numerical modelling of vibrationassisted turning of Ti-15333. Procedia CIRP. 2012a;1:347-52.

Muhammad R, Ahmed N, Shariff YM, Silberschmidt VV. Finite-element analysis of forces in drilling of Ti-alloys at elevated temperature. Solid State Phenomena. 2012b;188:250-5.

Muhammad R, Maurotto A, Roy A, Silberschmidt VV. Ultrasonically assisted turning of Ti-6Al-2Sn-4Zr-6Mo. Journal of Physics: Conference Series 2012c;382, 012016.

Nategh MJ, Razavi H, Abdullah A. Analytical modeling and experimental investigation of ultrasonic-vibration assisted oblique turning, part I: Kinematics analysis. International Journal of Mechanical Sciences. 2012;63:1-11.

Ozler L, Inan A, Ozel C. Theoretical and experimental determination of tool life in hot machining of austenitic manganese steel. International Journal of Machine Tools and Manufacture. 2001;41:163-72.

Pal DK, Basu SK. Hot machining of austenitic manganese steel by shaping. International Journal of Machine Tool Design and Research. 1971;11:45-61.

Shamoto E, Ma C, Moriwaki T. Elliptical vibration cutting (3rd report) - Application to three-dimensional cutting and investigation of practical effects. Seimitsu Kogaku Kaishi/Journal of the Japan Society for Precision Engineering. 1999;65:586-91.

Skelton RC. Turning with an oscillating tool. International Journal of Machine Tool Design and Research. 1968;8:239-59. 
Sun S, Harris J, Brandt M. Parametric investigation of laser-assisted machining of commercially pure titanium. Advanced Engineering Materials. 2008;10:565-72.

Uehara K, Sakurai M, Takeshita H. Cutting performance of coated carbides in electric hot machining of low machinability metals. CIRP Annals - Manufacturing Technology. 1983;32:97-100.

Weinert K, Inasaki I, Sutherland JW, Wakabayashi T. Dry machining and minimum quantity lubrication. CIRP Annals - Manufacturing Technology. 2004;53:511-37.

Yuan SM, Yan LT, Liu WD, Liu Q. Effects of cooling air temperature on cryogenic machining of Ti-6Al-4V alloy. Journal of Materials Processing Technology. 2011;211:356-62. 